\title{
Aspectos epidemiológicos, clínicos e parasitológicos da doença de Chagas em Mato Grosso do Sul
}

\author{
Epidemiological, clinical and parasitological aspects \\ of Chagas' disease in Mato Grosso do Sul State
}

\author{
Maurício Antonio Pompilio', Maria Elizabeth Moraes Cavalheiros Dorval', \\ Rivaldo Venâncio da Cunha ${ }^{3}$, Constança Britto ${ }^{4}$ e José Borges-Pereira ${ }^{5}$
}

\begin{abstract}
RESUMO
Com o objetivo de avaliar aspectos epidemiológicos, clínicos e parasitológicos da doença de Chagas crônica, em pacientes do Hospital Universitário da Universidade Federal de Mato Grosso do Sul, realizamos um estudo seccional envolvendo 120 chagásicos e 120 controles não-chagásicos, de ambos os sexos, com idades de 16 a 82 anos. Os aspectos epidemiológicos foram avaliados por questionário, a cardiopatia por exame clínico, eletrocardiograma convencional, radiologia e ecodopplercardiograma e a presença de Trypanosoma cruzi no sangue por xenodiagnóstico e teste da reação em cadeia da polimerase. Os resultados mostraram predominância de alóctones com baixa escolaridade e referência de contato prévio com triatomíneos entre os chagásicos. Abortamento espontâneo foi mais freqüente nas mulheres chagásicas. A cardiopatia devido ao componente chagásico foi estimada em 20,2\%. Apresentou-se com 7,5\% de cardiomegalia, 6,2\% de aneurisma de ventrículo esquerdo e com predominância de dispnéia, palpitações e hipertensão arterial. O xenodiagnóstico foi positivo em $26,1 \%$ dos chagásicos enquanto a PCR foi positiva em 53,7\%. A análise dos resultados indicou que a doença de Chagas no grupo estudado apresenta características clínicas e parasitológicas que revelam peculiaridades regionais.
\end{abstract}

Palavras-chaves: Doença de Chagas. Estudo transversal. Aspectos parasitológicos. Aspectos clínicos.

\begin{abstract}
With the objective of evaluating epidemiologic, clinical and parasitologic aspects of chronic Chagas' disease in patients from the University Hospital of the Federal University of Mato Grosso do Sul, a cross-sectional study was performed with groups of 120 chagasic and non-chagasic patients aged from 16 to 82 years. Epidemiologic aspects were evaluated by means of a questionnaire, cardiopathy by clinical examination, conventional electrocardiogram, radiology and Doppler echocardiograms (only in chagasic patients) and the presence of Trypanosoma cruzi in the blood stream by way of xenodiagnosis and polymerase chain reaction test. The results obtained indicated that the chagasic patients are predominantly alloctones with low-grade schooling, and were exposed to triatomines. The frequency of spontaneous abortion was higher in chagasic women. Chronic chagasic cardiopathy, estimated to occur in $20.2 \%$ of the patients, showed $7.5 \%$ cardiomegaly, $6.2 \%$ aneurysm of the left ventricle, and with a predominance of dyspnea, palpitations and arterial hypertension. Xenodiagnosis was positive for $26.1 \%$ of the chagasics and the PCR was positive for 53.7\%, and was significantly higher in males and alloctones. An analysis of the results shows that Chagas' disease, in the group studied, presented clinical and parasitologic characteristics demonstrating significant regional differences.
\end{abstract}

Key-words: Chagas' disease. Cross-sectional study. Parasitologic aspects. Clinical aspects.

\footnotetext{
1. Hospital Universitário da Universidade Federal de Mato Grosso do Sul, Campo Grande, MS. 2. Departamento de Patologia da Universidade Federal de Mato Grosso do Sul, Campo Grande, MS. 3. Serviço de Doenças Infecciosas e Parasitárias do Hospital Universitário da Universidade Federal de Mato Grosso do Sul, Campo Grande, MS. 4. Departamento de Bioquímica e Biologia Molecular do Instituto Oswaldo Cruz da Fundação Oswaldo Cruz, Rio de Janeiro, RJ. 5. Departamento de Medicina Tropical do Instituto Oswaldo Cruz da Fundação Oswaldo Cruz, Rio de Janeiro, RJ.

Apoio: CNPq e CAPES

Endereço para correspondência: Dr. Maurício Antonio Pompilio. Rua Tricordiano 496, 79051-150 Campo Grande, MS, Brasil.

Tel: 5567 341-8715

e-mail: pompilio@brturbo.com.br

Recebido para publicação em 3/8/2004

Aceito em 26/7/2005
} 
A história da doença de Chagas na região sul do antigo Estado de Mato Grosso e atual Mato Grosso do Sul (MS) teve seu início em 1918, com Chagas ${ }^{13}$ revelando a presença do Trypanosoma cruzi em animais como tatus. Enquanto os primeiros relatos sobre os triatomíneos das espécies Panstrongylus megistus e Triatoma sordida foram feitos por Neiva e Pinto em $1923^{24}$. No período de 1975 a 1979, Silva ${ }^{32}$ identificou casos humanos, reservatórios domésticos e silvestres na região de Fátima do Sul e registrou o encontro de Triatoma infestans naturalmente infectado nos domicílios rurais e de T. sordida, $R$. neglectus e $P$. geniculatus em biótopos naturais.

No Inquérito Sorológico Nacional ${ }^{11}$, sobre a doença de Chagas, realizado no período 1975-1980, estimou-se em 2,5\% a soroprevalência para todo Estado do Mato Grosso do Sul. Em seguida, no inquérito sorológico realizado em escolares de 7 a 14 anos, no período 1994-1997, estimou-se a soroprevalência em 0,05\% (dois casos em 3.891 examinados) ${ }^{33}$. Em 1999, a soropositividade $1,1 \%$ em primodoadores matriculados no Hemosul de Campo Grande, no período de julho/1984 a fevereiro/ 1985, foi definida por Aguiar e Aguiar ${ }^{2}$, ressaltando a ausência de caso autóctone. Em 2001, Borges-Pereira e cols ${ }^{9}$ encontraram $1,83 \%$ de soropositivos entre 14.709 moradores investigados no período de janeiro de 1998 a dezembro de 1999 na área urbana de 12 municípios do Distrito Sanitário de Rio Verde.

Sobre a morbidade, Pompilio e cols ${ }^{26}$, revisando 200 prontuários de pacientes chagásicos atendidos no ambulatório do Hospital Universitário da UFMS no período de 1986 a 1996 observou que $1 \%$ tinha diagnóstico de doença de Chagas aguda; 45,5\% forma crônica indeterminada; 39,5\% forma cardíaca crônica; $11 \%$ forma digestiva crônica e $3 \%$ forma mista (cardíaca e digestiva). No Distrito Sanitário de Rio Verde/MS, BorgesPereira e cols ${ }^{9}$ encontraram prevalência de $24,6 \%$ de cardiopatia devida exclusivamente ao componente chagásico.

Ampliar o conhecimento sistematizado da doença de Chagas no Estado de Mato Grosso do Sul e estimular o manejo clínico dos pacientes conduziram a realização do presente estudo com os seguintes objetivos: determinar a frequiência de miocardiopatia em chagásicos e controles não-chagásicos através do estudo eletrocardiográfico, a frequiência de aneurisma do ventrículo esquerdo nos chagásicos através do estudo ecocardiográfico, determinar a frequiência de positividade do xenodiagnóstico e do teste da reação em cadeia da polimerase.

\section{MATERIAL E MÉTODOS}

No período de maio/98 a novembro/99, 120 pacientes com sorologia positiva para a infecção chagásica foram atendidos no Hospital Universitário da Universidade Federal de Mato Grosso do Sul (HU-UFMS), Ambulatório de Doenças Infecciosas e Parasitárias (DIP), os quais foram informados sobre o projeto de pesquisa a ser realizado e, como voluntários, assinaram o consentimento que autoriza sua participação. Para serem incluídos no grupo de chagásicos foi necessária a positividade sorológica para a infecção chagásica em dois dos testes de hemaglutinação indireta (HAI), imunofluorescência indireta (IFI) e/ou ELISA. No mesmo período, com os candidatos a doação de sangue no HEMOSUL (Centro de Hematologia e Hemoterapia de Mato Grosso do Sul) e entre os pacientes do ambulatório de clínica médica do HU-UFMS foi formado um grupo controle constituído por indivíduos não-chagásicos, com os testes sorológicos negativos e idade média semelhante.

Aspectos epidemiológicos. Os pesquisadores aplicaram questionário abordando idade, sexo, naturalidade, escolaridade, atividade profissional, hemotransfusão, conhecimento e cohabitação com triatomíneos em todos os pacientes.

Aspectos clínicos. Todos os chagásicos e controles foram avaliados por anamnese e exame físico destinados aos aparelhos cardiovascular e digestivo. A hipertensão arterial foi considerada, em repouso, a partir de valores: sistólico igual ou maior que $160 \mathrm{mmHg}$ ou diastólico igual ou maior que $95 \mathrm{mmHg}$ de acordo com Ministério da Saúde ${ }^{23}$.

De chagásicos e controles foi obtido o registro eletrocardiográfico das doze derivações clássicas mais D2 longo em caso de arritmias; a leitura foi feita por dois examinadores conforme normas e critérios da NYHA (New York Heart Association $)^{25}$, considerando normais frequiências cardíacas de 50 a 120 bpm. Os ecodopplercardiogramas foram realizados em 113 chagásicos: 54 mulheres e 59 homens com idades de 16 a 79 anos (média = 45,9 anos), pelo serviço de cardiologia do HU-UFMS utilizando-se um ecocardiógrafo portátil. 0 exame incluiu cortes convencionais paraesternais, supra esternais, apicais e subcostais e variações dos cortes convencionais, com o objetivo de identificar alterações segmentares localizadas. A função sistólica global do ventrículo esquerdo (VE) foi avaliada ao modo $\mathrm{M}$ através do cálculo da fração de ejeção (FE) e ao bidimensional especialmente pelo caráter segmentar do acometimento miocárdico na doença de Chagas. 0 tipo de acometimento miocárdico foi definido como segmentar quando em pelo menos um segmento o déficit contrátil era significativamente mais acentuado do que nos demais, ou difuso quando todos os segmentos apresentavam déficit contrátil semelhante. Na análise segmentar foi utilizado o modelo preconizado por Schiller e cols ${ }^{30}$ e os segmentos foram classificados como normais, hipocinéticos, acinéticos e discinéticos de acordo com os critérios convencionais. A radiografia de tórax em póstero-anterior foi realizada em 120 chagásicos definindo cardiomegalia a partir de índice cardiotorácico (ICT) superior a 0,5 . Apenas alguns pacientes com queixas digestivas foram radiografados devido à limitação de recursos. A pesquisa de megaesôfago foi realizada em 12 chagásicos com queixa de disfagia através da técnica do esofagograma preconizada por Lauar e $\operatorname{cols}^{21}$ e a pesquisa de megacólon foi realizada em 16 chagásicos com queixa de constipação intestinal superior a cinco dias.

Aspectos parasitológicos. Foram avaliados através do xenodiagnóstico e pela técnica da reação em cadeia da polimerase. 0 xenodiagnóstico direto foi aplicado em 92 chagásicos utilizando-se 40 ninfas de $3^{\circ}$ e $4^{\circ}$ estádios de Triatoma infestans e/ou Rhodnius prolixus. Estes exames foram realizados no Laboratório de Parasitologia da UFMS e a leitura microscópica das dejeções obtidas por compressão 
abdominal ocorreu aos 30 e 60 dias após a aplicação. A técnica da PCR, realizada no Laboratório de Biologia Molecular e Doenças Endêmicas IOC/FIOCRUZ, foi aplicada em amostra de $10 \mathrm{ml}$ de sangue misturados imediatamente após a coleta, ao mesmo volume de solução de lise Guanidina-HCl 6M + EDTA 200mM, em 80 chagásicos crônicos, conforme os procedimentos adotados por Britto e cols ${ }^{10}$ empregando os primers 121 (5'-AAATAATGTACGGG(T/G) GAGATGCATGA-3') e 122 (5'-GGTTCGATTGGGGTTGGTGTAATATA-3') que amplificam um fragmento de 330 pares de bases $(\mathrm{pb})$ contendo as regiões hipervariáveis dos minicírculos do kDNA do parasito.

Análise estatística. Os dados foram avaliados pelo programa EPI-INFO versão 6.04b, considerando-se o nível de significância de 5\% para rejeitar a hipótese nula. Na estimativa do componente exclusivamente chagásico da cardiopatia avaliada pelo ECG foi utilizado o método de Sheps ${ }^{31}$, resumido na seguinte equação: $\mathrm{PC}=[(\mathrm{XC} / \mathrm{NC})-(\mathrm{X} 0 / \mathrm{N} 0)] \times(\mathrm{N} 0 / \mathrm{N} 0-\mathrm{X} 0)$

$\mathrm{PC}=$ proporção de cardiopatia, entre chagásicos, que podem ser atribuídas à doença de Chagas; XC = número de chagásicos com cardiopatia; $\mathrm{NC}=$ número total de chagásicos estudados; X0 = número de não-chagásicos com cardiopatia; N0 = número total de não-chagásicos estudados.

\section{RESULTADOS}

Aspectos epidemiológicos. 0 grupo de chagásicos em comparação com o de não-chagásicos apresentou maiores freqüências de indivíduos alóctones (65\%), com escolaridade fundamental $(69,1 \%)$, história de ter morado na área rural $(88,3 \%)$, de conhecer os barbeiros $(59,2 \%)$ e de ter cohabitado com estes insetos (50\%). 0 abortamento espontâneo foi referido, respectivamente, por $24(42,9 \%)$ e $9(16,1 \%)$ mulheres chagásicas e não-chagásicas $(\mathrm{p}=0,018)$.

Aspectos clínicos. A média das manifestações clínicas no grupo de chagásicos de 3,3 foi significativamente maior do que a média de 1,7 no grupo de não-chagásicos, do mesmo modo que o observado nas médias das manifestações cardiovasculares e digestivas (Tabela 1). Ressaltam-se as maiores diferenças para dispnéia, palpitações, disfagia, regurgitações e constipação intestinal maior que 10 dias. A hipertensão arterial foi mais freqüente no grupo de chagásicos e estatisticamente significativa na faixa etária de 40 a 59 anos (Tabela 2).

No grupo de chagásicos foram identificados 57 (47,5\%) ECG alterados, enquanto no grupo de não-chagásicos foram identificados $41(34,2 \%)$, diferença esta estatisticamente significativa $(\mathrm{p}=0,035)$, indicando um risco absoluto ou gradiente de $13,3 \%$ e um risco relativo de 1.4 . Ao aplicarmos 0 método das proporções de Sheps ${ }^{31}$ para estimar a proporção de participação do componente etiológico exclusivamente chagásico na prevalência de ECG alterados entre os chagásicos encontramos 20,2\%, prevalência esta que pode ser considerada como a estimada para a cardiopatia chagásica crônica no grupo estudado. Ao compararmos as frequiências de ECG alterados do grupo de chagásicos com as do grupo de não-chagásicos, observamos que as diferenças não foram estatisticamente significativas, em relação à naturalidade, sexo, faixa etária e pressão arterial. Entretanto, no grupo de não-chagásicos a freqüência de ECG alterado foi significativamente maior no grupo de pacientes alóctones em comparação com os autóctones. Na análise das freqüências dos tipos de alterações eletrocardiográficas (Tabela 3), foi verificado o registro de 101 alterações no grupo de chagásicos, indicando uma média de 0,8 alterações/ paciente, enquanto no grupo de não-chagásicos verificamos um total de 69 alterações, indicando uma média de 0,6 alterações/paciente, 1.5 vezes menor do que no grupo de chagásicos. No grupo de chagásicos predominaram as alterações da repolarização ventricular, bloqueio completo do ramo direito, hemibloqueio anterior esquerdo, extrasístoles ventriculares e os bloqueios aurículo-ventricular,

\begin{tabular}{|c|c|c|c|c|c|c|}
\hline \multirow[t]{2}{*}{ Manifestações clínicas } & \multicolumn{2}{|c|}{$\begin{array}{c}\text { Chagásicos } \\
\mathrm{n}=120\end{array}$} & \multicolumn{2}{|c|}{$\begin{array}{c}\text { Não-chagásicos } \\
\mathrm{n}=120\end{array}$} & \multirow[t]{2}{*}{ Gradiente } & \multirow[t]{2}{*}{$P$} \\
\hline & $\mathrm{n}^{\underline{0}}$ & $\%$ & $\mathrm{n}^{\mathrm{o}}$ & $\%$ & & \\
\hline Cardiovasculares & 256 & & 147 & & & \\
\hline dispnéia aos esforços & 49 & 40,8 & 24 & 20,0 & 20,8 & 0,0004 \\
\hline hipertensão arterial & 43 & 35,8 & 20 & 16,7 & 19,1 & 0,001 \\
\hline palpitação em repouso & 34 & 28,3 & 20 & 16,7 & 11,6 & 0,03 \\
\hline palpitação aos esforços & 44 & 36,6 & 18 & 15,0 & 21,6 & 0,0001 \\
\hline dor precordial em repouso & 17 & 14,2 & 15 & 12,5 & 1,7 & Ns \\
\hline dor precordial aos esforços & 26 & 21,6 & 15 & 12,5 & 9,1 & Ns \\
\hline perda da consciência & 4 & 3,3 & 2 & 1,6 & 1,7 & Ns \\
\hline ictus desviado & 5 & 4,2 & 1 & 0,8 & 3,4 & Ns \\
\hline bradicardia & 1 & 0,8 & 3 & 2,5 & 1,7 & Ns \\
\hline arritmia à ausculta & 10 & 8,3 & 9 & 7,5 & 0,8 & Ns \\
\hline sopro sistólico & 9 & 7,5 & 4 & 3,3 & 4,2 & Ns \\
\hline sopro diastólico & 3 & 2,5 & 2 & 1,7 & 0,8 & Ns \\
\hline desdobramento de b1 ou b2 & 5 & 4,1 & 6 & 5,0 & 0,9 & Ns \\
\hline edema de membros inferiores & 6 & 5,0 & 8 & 6,7 & 1,7 & Ns \\
\hline Digestivas & 139 & & 58 & & & \\
\hline pirose & 41 & 34,2 & 20 & 16,7 & 17,5 & 0,001 \\
\hline disfagia & 18 & 15,0 & 4 & 3,3 & 11,7 & 0,001 \\
\hline odinofagia & 10 & 8,3 & 7 & 5,8 & 2,5 & Ns \\
\hline regurgitação & 22 & 18,2 & 3 & 2,5 & 15,7 & 0,0001 \\
\hline obstipação intestinal de 5-10dias & 14 & 11,6 & 9 & 7,5 & 4,1 & Ns \\
\hline obstipação intestinal > 10 dias & 6 & 5,0 & 0 & - & - & \\
\hline uso de laxativo & 28 & 23,3 & 14 & 11,7 & 11,6 & 0,017 \\
\hline sigmóide palpável & 0 & - & 1 & 0,8 & - & \\
\hline
\end{tabular}

Ns = diferença estatisticamente não significativa

Tabela 2 - Distribuição dos casos de hipertensão arterial por faixa etária em chagásicos crônicos e não chagásicos, HU-UFMS, maio/98 a novembro/99.

\begin{tabular}{lrrrrrr}
\hline & \multicolumn{4}{c}{ Sorologia } \\
\cline { 2 - 3 } Faixa etária & \multicolumn{2}{c}{ chagásicos } & & \multicolumn{2}{c}{ não chagásicos } & \\
\cline { 2 - 3 } & $\mathrm{n}^{0}$ & $\%$ & & $\mathrm{n}^{0}$ & $\%$ & $\mathrm{p}$ \\
\hline$<20$ & - & - & & - & - \\
$20-39$ & 7 & 18,4 & & 2 & 4,4 & 0,09 \\
$40-59$ & 28 & 45,2 & & 11 & 23,9 & 0,02 \\
260 & 8 & 44,4 & & 7 & 26,9 & 0,22 \\
\hline Total & 43 & 35,8 & & 20 & 16,7 & $<0,001$ \\
\hline
\end{tabular}


enquanto no grupo de não chagásicos predominaram as alterações da repolarização ventricular e a sobrecarga ventricular esquerda (Tabela 3). Ao considerarmos anormais somente os ECG com registro de uma ou mais das alterações consideradas características da cardiopatia chagásica crônica: bloqueio completo do ramo direito + hemibloqueio anterior esquerdo, extra-sístoles ventriculares complexas, bloqueio aurículo-ventricular e zona eletricamente inativa, observamos prevalência de ECG alterado de $20,8 \%$ (25 casos) no grupo de chagásicos e de 4,2\% (5 casos) no grupo de não-chagásicos, indicando um gradiente de 16,6\% e um risco relativo 5 vezes maior para o grupo de chagásicos apresentar essas alterações.

\begin{tabular}{|c|c|c|c|c|c|c|}
\hline \multirow[t]{2}{*}{ Manifestações clínicas } & \multicolumn{2}{|c|}{$\begin{array}{c}\text { Chagásicos } \\
\text { n= } 120\end{array}$} & \multicolumn{2}{|c|}{$\begin{array}{c}\text { Não-chagásicos } \\
n=120\end{array}$} & \multirow[t]{2}{*}{ Gradiente* } & \multirow[t]{2}{*}{$\mathrm{P}$} \\
\hline & $\mathrm{n}^{0}$ & $\%$ & $\mathrm{n}^{0}$ & $\%$ & & \\
\hline Bradicardia sinusal & 0 & - & 4 & 3,3 & - & \\
\hline Fibrilação auricular & 0 & - & 3 & 2,5 & - & \\
\hline Extra-sístoles supraventriculares & 4 & 3,3 & 4 & 3,3 & 0 & Ns \\
\hline Extra-sístoles v. monomórficas ${ }^{* * *}$ & 7 & 5,8 & 2 & 1,7 & 4,1 & Ns \\
\hline Extra-sístoles v. polimórficas & 2 & 1,7 & 1 & 0,8 & 0,9 & Ns \\
\hline Extra-sístoles v. bigeminadas & 2 & 1,7 & 0 & - & - & \\
\hline Baixa voltagem de QRS & 1 & 0,8 & 2 & 1,7 & 0,9 & Ns \\
\hline Bloqueio aurículo-ventricular I & 6 & 5,0 & 1 & 0,8 & 4,2 & Ns \\
\hline Bloqueio aurículo-ventricular II & 2 & 1,7 & 0 & - & - & \\
\hline Bloqueio aurículo-ventricular III & 1 & 0,8 & 0 & - & - & \\
\hline Bloqueio do ramo direito I & 6 & 5,0 & 4 & 3,3 & 1,7 & Ns \\
\hline Bloqueio do ramo direito II & 3 & 2,5 & 0 & - & - & \\
\hline Bloqueio do ramo direito III & 12 & 10,0 & 0 & - & - & \\
\hline Bloqueio do ramo esquerdo I & 2 & 1,7 & 0 & - & - & \\
\hline Bloqueio do ramo esquerdo II & 2 & 1,7 & 0 & - & - & \\
\hline Hemibloqueio anterior esquerdo & 12 & 10,0 & 6 & 5,0 & 5,0 & Ns \\
\hline Distúrbio da repol. v. difuso & 18 & 15,0 & 23 & 19,2 & 4,2 & Ns \\
\hline Distúrbio da repol. v. segmentar & 7 & 5,8 & 7 & 5,8 & 0 & Ns \\
\hline Sobrecarga auricular esquerda & 7 & 5,8 & 2 & 1,7 & 4,1 & Ns \\
\hline Sobrecarga ventricular esquerda & 3 & 2,5 & 7 & 5,8 & 3,3 & Ns \\
\hline Zona eletricamente inativa anterior & 3 & 2,5 & 1 & 0,8 & 1,7 & Ns \\
\hline Zona eletricamente inativa inferior & 1 & 0,8 & 2 & 1,7 & 0,9 & Ns \\
\hline
\end{tabular}

*diferença entre os percentuais; *** ventricular; $\mathrm{p} \leq 0,05=$ diferença estatisticamente significativa; Ns = diferença estatisticamente não significativa

Foram registrados $27(23,8 \%)$ ecocardiogramas anormais entre os 113 chagásicos examinados, com frequiências crescentes com a faixa etária e sem diferenças significativas em relação ao sexo. Entre as anormalidades predominaram as de natureza segmentar, representadas principalmente pelas hipocinesias em $12(10,6 \%)$ casos e discinesias ou aneurismas de ventrículo esquerdo da região apical em 7 (6,2\%) casos, sendo que as primeiras não foram associadas as alterações radiográficas. A função ventricular esteve alterada em $20(17,7 \%)$ e a fração de ejeção $<50 \%$ foi identificada em $7(6,2 \%)$ pacientes. Cabe ressaltar que todos os pacientes com aneurismas de VE apresentaram ECG alterados, entre os quais dois com importante redução da fração de ejeção.

Dos 120 chagásicos crônicos avaliados com radiografia panorâmica do tórax, 9 (7,5\%) apresentaram cardiomegalia, ressaltando que somente um paciente apresentou ECG normal e que em $7(77,8 \%)$ destes o ecocardiograma foi alterado. No esofagograma realizado de modo seletivo em 12 pacientes com disfagia foram detectados 7 (58,3\%) casos com megaesôfago, apenas um paciente era autóctone, enquanto no enema opaco também seletivo em 16 pacientes com constipação intestinal foram detectados $9(56,2 \%)$ casos de megacólon, sendo dois naturais de Mato Grosso do Sul (Tabela 4).

Tabela 4 - Características dos pacientes chagásicos crônicos com megaesôfago e/ ou megacólon confirmados por exames radiológicos, $\mathrm{HU}$-UFMS, maio/98 a novembro/99.

\begin{tabular}{lccccc}
\hline & & Natural & \multicolumn{2}{c}{ Radiografia } & \\
\cline { 4 - 5 } Sexo* $^{n}$ & Idade & Estado & Megaesôfago** & Megacólon & ECG \\
\hline M & 72 & GO & não & sim & alterado \\
F & 57 & BA & I & não & normal \\
F & 69 & PI & não & sim & alterado \\
M & 79 & PI & III & sim & alterado \\
M & 45 & MS & III & sim & alterado \\
F & 29 & MS & não & sim & normal \\
F & 64 & MG & II & sim & alterado \\
F & 34 & MG & III & não & normal \\
M & 55 & SP & III & não & normal \\
F & 29 & SP & não & sim & normal \\
F & 57 & SP & não & sim & normal \\
M & 68 & SP & II & sim & alterado \\
\hline
\end{tabular}

*M: masculino; F: feminino *** grupo radiológico segundo Rezende ${ }^{27}$

Aspectos parasitológicos. Dos 92 chagásicos submetidos ao xenodiagnóstico, 24 (26,1\%) foram positivos, enquanto dos 80 que realizaram o teste PCR, em 43 (53,7\%) o exame foi positivo $(p=0,0002)$. Dos 61 pacientes que realizaram os dois exames, $24(39,3 \%)$ apresentaram ambos os exames negativos e 37 (60,7\%) demonstraram positividade em um ou nos dois exames, indicando parasitemia no momento da obtenção do sangue. Contudo, merece destaque a positividade do xenodiagnóstico e negatividade da PCR em 5 pacientes chagásicos crônicos. Os resultados negativos pela PCR foram posteriormente confirmados utilizando-se um outro ensaio molecular com primers desenhados para o gene da $\beta$-globina humana como teste confirmatório para demonstrar a ausência de possíveis agentes inibitórios nas amostras de DNA testadas, que pudessem comprometer a atividade da enzima DNA polimerase ${ }^{29}$.

\section{DISCUSSÃO}

$\mathrm{Na}$ análise do perfil epidemiológico dos chagásicos do presente estudo, encontramos predominância de alóctones procedentes principalmente de áreas rurais com baixa escolaridade e antecedente de intenso contato com os triatomíneos. Este perfil não difere do referido nos estudos da mesma natureza contidos na literatura, ressaltando que a maior participação de alóctones em nossa casuística expressa características da população de Mato Grosso do Sul, constituída por parcela significativa de migrantes de outras 
regiões, principalmente do sul do Brasil. A maior frequiência de abortamento espontâneo entre as chagásicas é um dado em concordância com os resultados em São Felipe, Bahia ${ }^{5}$ em divergência com os resultados obtidos no Sertão da Paraíba, porém fatores nutricionais e etários da ocasião do aborto não foram estudados o que não permite caracterizar diferenças regionais dependentes do agravo.

No exame clínico evidenciamos a dispnéia, palpitações e regurgitações como as manifestações clínicas mais frequientes entre os chagásicos em comparação com os não-chagásicos, semelhante aos resultados de estudos da mesma natureza realizados em amostras rurais ${ }^{41418} \mathrm{ou}$ em amostras residentes em grandes centros urbanos $^{1735}$. Não temos explicação consistente para a maior prevalência de hipertensão arterial nos chagásicos. Diverge dos resultados de estudos como os de Castro ${ }^{12}$ em Mambaí-GO, Dubois ${ }^{18}$ em Virgem da Lapa-MG e Arruda Junior ${ }^{3}$ em Aguiar e Bouqueirão dos Cochos na Paraíba, que não encontraram diferença significativa entre chagásicos e não-chagásicos. Assim como se mostra significativamente maior do que a prevalência de $18 \%$ encontrada por Xavier ${ }^{35}$.

O comprometimento do miocárdio avaliado através do ECG indicou um gradiente de $13,3 \%$ para os chagásicos. Este gradiente estatisticamente significativo é semelhante aos valores estimados para os chagásicos dos Estados da Paraíba, Pernambuco $^{22}$ e de áreas endêmicas do sul do Rio Grande do $\mathrm{Sul}^{4}$, abaixo dos valores estimados para os Estados de Minas Gerais, Paraná, Bahia e Goiás ${ }^{22}$ e acima dos valores para os Estados de Sergipe, Alagoas e Ceará22, a partir dos dados do inquérito eletrocardiográfico nacional. A frequiência de ECG alterados no grupo de não-chagásicos da nossa casuística é maior do que os valores encontrados nos estudos dos autores citados, influindo de modo significativo no gradiente.

A participação do componente etiológico exclusivamente chagásico na prevalência de ECG alterados foi estimada em torno de $20 \%$, valor este que pode ser atribuído à infecção pelo T. cruzi, o qual foi confirmado no próprio estudo ao encontrarmos 20,8\% de ECG com as alterações consideradas características da miocardiopatia chagásica crônica. Estas considerações adquirem importância na medida em que podem com maior fidelidade dimensionar a magnitude da interação hospedeiro-parasita nas diferentes regiões endêmicas, permitindo caracterizar as diferenças regionais na morbidade cardíaca. Entretanto a hipertensão arterial também contribui no determinismo da prevalência de ECG alterados entre os chagásicos. Em nosso estudo, 23,3\% dos exames apresentaram anormalidades, enquanto BorgesPereira e cols ${ }^{8}$ em estudo realizado em Virgem da Lapa, MG, encontraram 30,2\% em uma população não selecionada de 298 chagásicos crônicos e Xavier ${ }^{35}$ encontrou 31\%. Do mesmo modo que o observado por esses autores, a frequiência de ecocardiogramas anormais aumentou com a idade, todavia sem diferença em relação ao sexo dos pacientes. Por outro lado, essas prevalências de ecocardiogramas anormais são significativamente menores do que as encontradas em estudos com grupos de chagásicos selecionados ${ }^{19}$. A presença do aneurisma de ventrículo esquerdo, como marcador de gravidade da cardiopatia chagásica crônica, foi identificada em 6,2\% dos chagásicos, todos com alterações eletrocardiogáficas. Nos estudos de Borges-Pereira e cols ${ }^{8} \mathrm{e}$ de Xavier ${ }^{35}$ foram identificados, respectivamente 18,8\% e 16\% de aneurismas de ventrículo esquerdo, indicando a maior gravidade da cardiopatia chagásica entre os pacientes avaliados por estes autores, o que também fica evidenciado no estudo eletrocardiográfico realizado por Borges-Pereira ${ }^{6}$ no qual registrou $37,8 \%$ de miocardiopatia atribuíveis ao componente etiológico chagásico e Xavier ${ }^{35}$ identificou 57\% de miocardiopatia entre os chagásicos de sua casuística.

Outro elemento indicativo da gravidade da cardiopatia é a presença de cardiomegalia ao exame radiológico. Em nosso estudo encontramos 7,5\% dessa alteração entre os chagásicos, menor do que os percentuais acima de $10 \%$ encontrados em estudos com amostras não selecionadas desenvolvidos em áreas endêmicas de Minas Gerais e Piau1 ${ }^{15}$ e em amostras não selecionadas com paciente de diversos estados do Brasil ${ }^{1635}$. 0 comprometimento do aparelho digestivo na infecção chagásica foi confirmado em alóctones e em autóctones pela identificação radiológica de megaesôfago e megacólon, referido por Rezende ${ }^{28}$ sobre ocorrência desta forma clínica da região centro-oeste do Brasil. A não realização dos exames em todos os chagásicos dificultou a análise sobre a prevalência destas manifestações da forma digestiva da doença de Chagas.

Em nosso estudo foram identificados $26,1 \%$ de xenodiagnósticos positivos, sem diferença significativa em relação à naturalidade e sexo dos pacientes, contudo a frequiência foi significativamente menor entre os pacientes com idades de 40 a 59 anos. 0 confronto desses dados com os de outros trabalhos mostra que este percentual de positividade dos xenodiagnósticos não difere dos percentuais encontrados em áreas endêmicas de Minas Gerais ${ }^{15}$, apesar das diferenças em relação à metodologia como espécies empregadas e o modo de leitura das ninfas. Todavia, o percentual é significativamente maior do que os $13 \%$ encontrados em chagásicos de áreas endêmicas do Sertão da Paraíba ${ }^{7}$ e significativamente menor do que os $36 \%$ encontrados por Castro ${ }^{12}$ entre os chagásicos de Mambaí-G0. No global a positividade do xenodiagnóstico foi menor do que a do teste da PCR, comportamento semelhante aos referidos em estudos envolvendo estes dois exames, independentemente da região de origem dos pacientes ${ }^{10} 2034$. Entretanto, alguns aspectos merecem destaque em nosso trabalho, por exemplo, a diferença não significativa entre as positividades de ambos os exames nos pacientes autóctones. Outro aspecto não menos importante foi o achado de maior positividade do teste da PCR entre alóctones em comparação com os autóctones, enquanto a positividade do xenodiagnóstico não mostrou diferenças significativas nos dois grupos de pacientes. Não temos explicação consistente para o achado, porém, podemos especular em torno da menor sensibilidade dos triatomíneos empregados à infecção pelas formas de T. cruzi circulantes entre os alóctones ou em torno da maior sensibilidade do teste da PCR em decorrência da amplificação gênica a partir de outras formas circulantes do parasita. 0 achado de cinco pacientes com negatividade do teste da PCR e positividade do xenodiagnóstico pode relacionar-se com a obtenção do material para os dois exames em momentos distintos. 


\section{REFERÊNCIAS BIBLIOGRÁFICAS}

1. Acquatella H, Schiller NB, Puigbó JJ, Giordano H, Suarez JA, Casal H, Arreaza N, Valecillos R, Hirschhaut E. M-mode and two-dimensional echocardiography in chronic Chagas heart disease. Circulation 62:787795,1980 .

2. Aguiar JI, Aguiar ES. Serologic testing for Chagas' disease and HIV in counseling programs and blood banks in Midwest Brasil. The Brazilian Journal of Infectious Diseases 3:176-179, 1999.

3. Arruda Junior ER. Estudo sobre a doença de Chagas nos municípios de Aguiar e Boqueirão dos Cochos, Vale do Piancó, Estado da Paraíba. Dissertação de mestrado, Universidade Federal do Rio de Janeiro, Rio de Janeiro, RJ, 1981.

4. Baruffa G, Alcantara A, Aquino Neto JO. Estudo pareado da cardiopatia chagásica no Rio Grande do Sul, Brasil. Memórias do Instituto Oswaldo Cruz 80: 457-462, 1985.

5. Batista C, Teixeira G, Macedo V. Prevalência de abortamento e prematuridade em uma área endêmica para doença de Chagas. In: Anais do XVI Congresso da Sociedade Brasileira de Medicina Tropical, Natal p. 50,1980 .

6. Borges-Pereira J. Doença de Chagas humana: estudo da infecção crônica, morbidade e mortalidade em Virgem da Lapa, Minas Gerais, Brasil (19761996). Tese de Doutorado, Instituto Oswaldo Cruz, Rio de Janeiro, RJ, 1997

7. Borges-Pereira J, Coura JR. Morbidade da doença de Chagas em populações urbanas do Sertão da Paraíba. Revista da Sociedade Brasileira de Medicina Tropical 20:101-107, 1987

8. Borges-Pereira J, Xavier SS, Pirmez C, Coura JR. Doença de Chagas em Virgem da Lapa, Minas Gerais, Brasil. IV- Aspectos clínicos e epidemiológicos do aneurisma ventricular esquerdo. Revista da Sociedade Brasileira de Medicina Tropical 31:457-463, 1998.

9. Borges-Pereira J, Zauza PL, Galhardo MC, Nogueira JS, Pereira GRL, Cunha RV. Doença de Chagas na população urbana do Distrito Sanitário de Rio Verde, Mato Grosso do Sul, Brasil. Revista da Sociedade Brasileira de Medicina Tropical 34:459-466, 2001.

10. Britto C, Cardoso MA, Ravel C, Santoro A, Borges-Pereira J, Coura JR, Morel CM, Wincker P. Trypanosoma cruzi: Parasite detection and strain discrimination in chronic chagasic patients from Northeastern Brazil using PCR amplification of kinetoplast DNA and nonradiactive hybridization. Experimental Parasitology 81:462-471, 1995

11. Camargo ME, Silva GR, Castilho EA, Silveira AC. Inquérito sorológico da prevalência da infecção chagásica no Brasil 1975/1980. Revista do Instituto de Medicina Tropical de São Paulo 26:192-204, 1984

12. Castro CN. Influência da parasitemia no quadro clínico da doença de Chagas. Revista de Patologia Tropical 9:73-136, 1980.

13. Chagas C. Papel do tatu (Tatusia novemcincta) na transmissão do Trypanosoma cruzi. Revista Médica Cirúrgica do Brasil 26:220-223, 1918.

14. Correia-Lima FG. Doença de Chagas no município de Oeiras, Piauí. Estudo seccional nas localidades de Colônia e Oitis. Dissertação de Mestrado, Universidade Federal do Rio de Janeiro, Rio de Janeiro, RJ, 1976.

15. Coura JR, Abreu LL, Dubois LEG, Correia-Lima F, Arruda Junior ER, Willcox HPF, Anunziato N, Petana W. Morbidade da doença de Chagas. II - Estudos seccionais em quatro áreas de campo do Brasil. Memórias do Instituto Oswaldo Cruz 79:101-124, 1984.

16. Coura JR, Anunziato N, Willcox HPF. Morbidade da doença de Chagas. IEstudo de casos procedentes de vários Estados do Brasil, observados no Rio de Janeiro. Memórias do Instituto Oswaldo Cruz 78:363-372, 1983.

17. Dias JCP. Doença de Chagas em Bambuí, Minas Gerais, Brasil. Estudo clínicoepidemiológico a partir da fase aguda entre 1940 e 1982. Tese de Doutorado, Faculdade de Medicina da Universidade Federal de Minas Gerais, MG, 1982.
18. Dubois LE. Morbidade da doença de Chagas. Estudo seccional em uma área endêmica. Tese de Mestrado, Faculdade de Medicina da Universidade Federal do Rio de Janeiro, Rio de Janeiro, RJ, 1977.

19. Granzotti JA, Marin Neto JA, Gallo Junior I, Manco JC, Rassi A, Amorim DS Contribuição ao estudo do "aneurisma" da ponta na cardiopatia chagásica crônica. Arquivos Brasileiros de Cardiologia 27:477-484, 1974.

20. Junqueira ACV, Chiari E, Wincker P. Comparison of the polymerase chain reaction with two classical parasitological methods for the diagnosis of Chagas' disease in an endemic region of north-eastern Brazil. Transaction of the Royal Society of Tropical Medicine and Hygiene 90:129-132, 1996.

21. Lauar KM, Oliveira R, Rezende JM. Valor do tempo de esvaziamento esofagiano no diagnóstico da esofagopatia chagásica (prova de retenção). Revista Goiana de Medicina 5:97-102, 1959.

22. Macedo V, Prata A, Silva GR, Castilho E. Prevalência de alterações eletrocardiográficas em chagásicos. (Informações preliminares sobre 0 inquérito eletrocardiográfico nacional). Arquivos Brasileiros de Cardiologia 38:261-264, 1982.

23. Ministério da Saúde. Normas técnicas para o programa nacional de educação e controle de hipertensão. Ministério da Saúde, Brasília, no $47,1988$.

24. Neiva A, Pinto C. Representantes dos gêneros Triatoma Lap, Rhodnius Stal encontrados no Brasil Central e Sul; observações biológicas e descrição de uma nova espécie. Brasil Médico 37:84-86, 1923.

25. New York Heart Association (NYHA). Nomenclature and criteria for diagnosis of disease of the heart and great vessels. $7^{\text {th }}$ edition. Little and Brow Company, Boston, 1973.

26. Pompilio MA, Paniago AMM, Borges-Pereira J, Silva FAD, Silva RCB, Lima JHF. Análise clínica-epidemiológica de 200 casos de doença de Chagas atendidos no HU-UFMS de 1986-1996. Revista da Sociedade Brasileira de Medicina Tropical 31 (supl I):214, 1998.

27. Rezende JM, Lauar KL, Oliveira AR. Aspectos clínicos e radiológicos da aperistalsis do esôfago. Revista Brasileira de Gastroenterologia 12:247$262,1960$.

28. Rezende JM. Manifestações digestivas da doença de Chagas. In: Brener Z, Andrade Z (ed) Trypanosoma cruzi e doença de Chagas, Guanabara Koogan, Rio de Janeiro, p. 312-361, 1979.

29. Saiki RK, Scharf S, Faloona F, Mullis KB, Horn GT, Erlich HA, Arnheim N. Enzymatic amplification of â-globin genomic sequences and restriction site analysis for diagnosis of sickle cell anemia. Science 230:1350-1354, 1985.

30. Schiller NB, Shah FM, Crowford M, DeMaria A, Devereux R, Feigenbaum H, Gutfesell H, Reichek N, Shah DJ, Schnittger I, Silverman NH, Tajik AJ. Recommendations for quantitation of the left ventricle by two-dimensional echocardiography. The Journal of American Society of Echocardiography 2:358-367, 1989.

31. Sheps MC. An examination of some methods of comparing several rates of proportions. Biometrics 15:87-97, 1959.

32. Silva RP. Estudo sobre Trypanosoma (Schizotrypanum) cruzi (Chagas, 1909) em área de Mato Grosso do Sul: casos humanos, reservatórios e transmissores. Tese de Doutorado, Universidade de São Paulo, São Paulo, SP, 1979.

33. Silveira AC, Vinhaes M. Doença de Chagas: Aspectos epidemiológicos e de controle. Revista da Sociedade Brasileira de Medicina Tropical 31 (supl II): 15-60, 1998.

34. Wincker P, Britto C, Borges-Pereira J, Cardoso MA, Oelemann W, Morel $\mathrm{CM}$. Use of a simplified polymerase chain reaction procedure to detect Trypanosoma cruzi in blood samples from chronic chagasic patients in a rural endemic area. American Journal of Tropical Medicine and Hygiene 51:771-777, 1994

35. Xavier SS. Estudo longitudinal da morbi-mortalidade cardíaca da doença de Chagas em uma coorte de um grande centro urbano: análise clínica, eletrocardiográfica, radiológica e ecocardiográfica de 604 casos. Tese de Doutorado, Universidade Federal do Rio de Janeiro, Rio de Janeiro, RJ, 1999. 